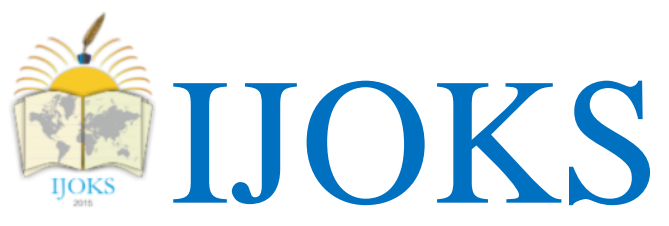

International Journal of Kurdish Studies

(ISSN:2149-2751)

$5(1)$, pp. $1-10$

http://www.ijoks.com

\title{
A Study of the concept of law from John Locke's point of view - An Examination of the reality of law in Kurdistan Region: "A Theoretical Study"
}

Asrin Zrar QADER \& Salim P.ALIAS ${ }^{2}$

Received: Mar 18, 2018 Reviewed: Mar 22, 2018 Accepted: Apr 25, 2018

\begin{abstract}
The law is the standard model of power that legal governments and recognized states possess. In democratic and civilized societies, law — as the opposite of force plays a significant role in conflict resolution. The rule of law obliges the state and state structures to obey the laws; this is how justice and equity is manifested in political systems and governing systems. Once authority is directed based on the rule of law and justice, human rights will be guaranteed, protected, and legally recognized. Rationality is the very essence of law. That is why British philosopher John Locke tried to reform the existing political system to be more based on rationality. He clearly proposed this idea in his "social contract" theory, which went on to become the standard source of legal authority later throughout civilized societies. Hence, it seems that French philosopher Voltaire was affected by Locke's ideas, as he believed that law is a rational guide in a world where rationality is absent.
\end{abstract}

Key words: Law, Political Authority, Social Justice, Human rights, Equality

\section{Recommended citation:}

Qader, A. Z. \& Alias, S.P. (2019). A Study of the concept of law from John Locke's point of view — An Examination of the reality of law in Kurdistan Region: "A Theoretical Study". International Journal of Kurdish Studies 5 (1), 1 - 10 DOI: 10.21600/ijoks.516467

\footnotetext{
${ }^{1}$ Correspondent Author: Lecture, Department of Sociology, College of Arts, Salahaddin University- Erbil, Kurdistan Region- Iraq. E.mail: asrin.qader@su.edu.krd, ORCID NO: https://orcid.org/0000-0003-4353-2472

${ }^{2}$ Assistant Prof. Dr., Department of Sociology, College of Arts, Salahaddin University- Erbil, Kurdistan RegionIraq. E.mail: salim.alias@ su.edu.krd,
} 


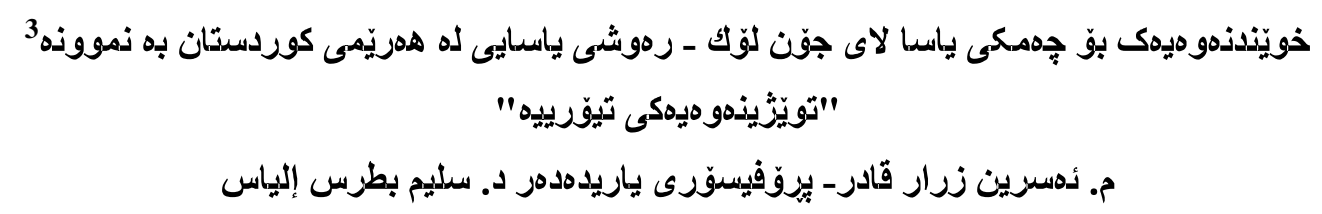

بِيشدهكى

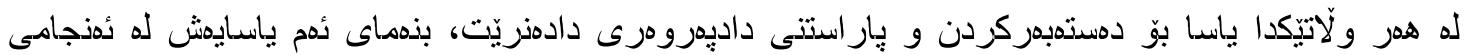

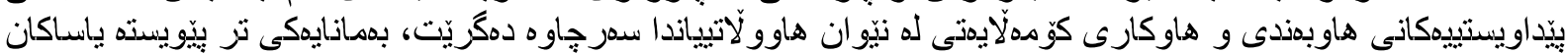

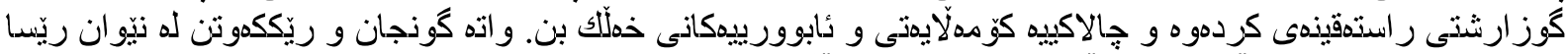

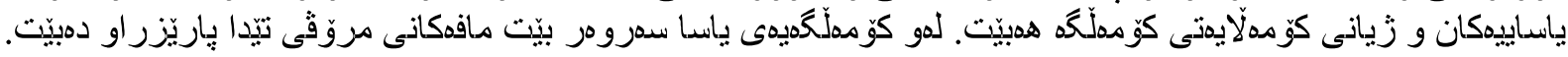

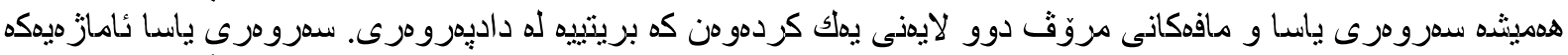

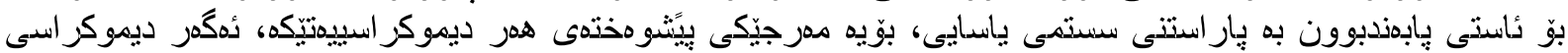

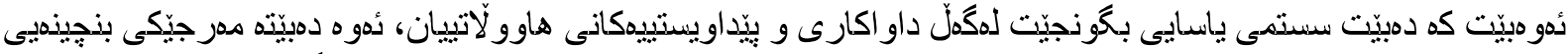

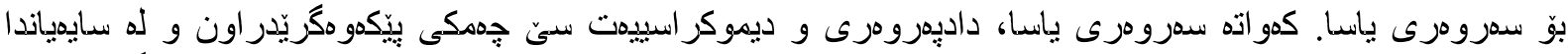

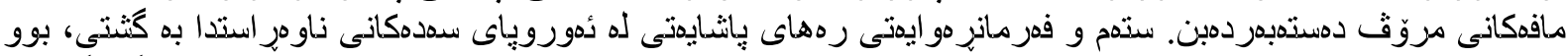

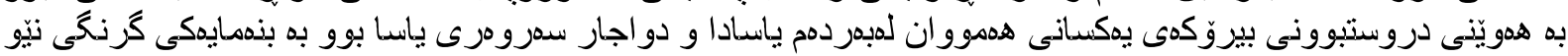

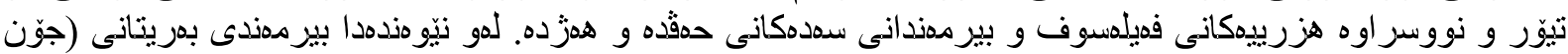

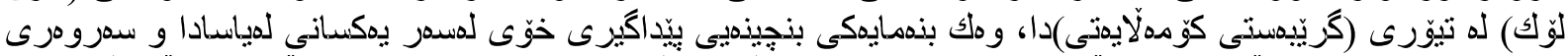

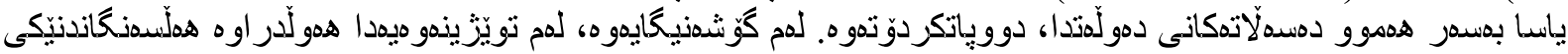

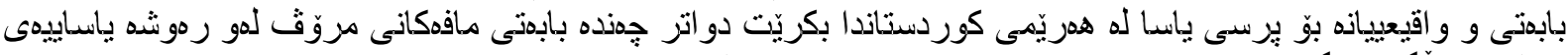

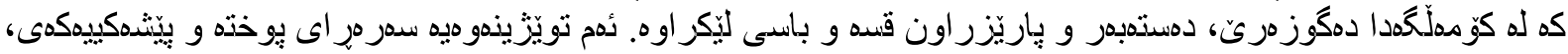

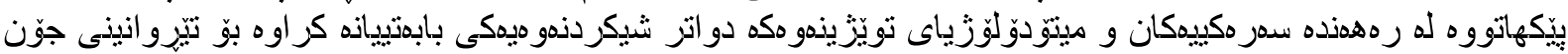

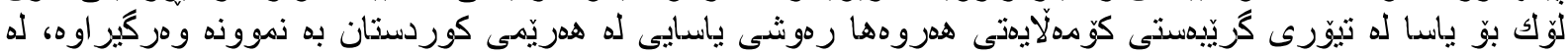

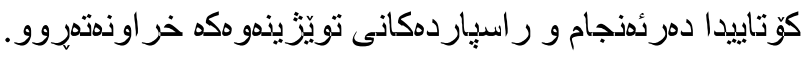

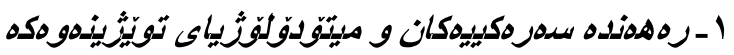

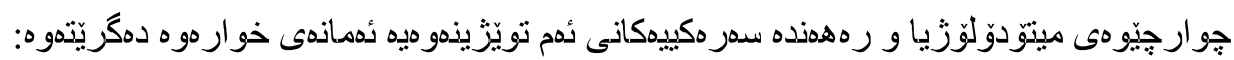

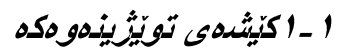

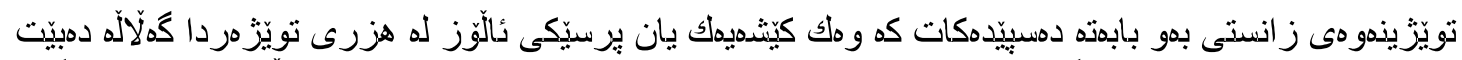

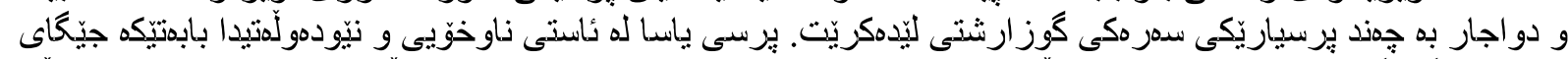

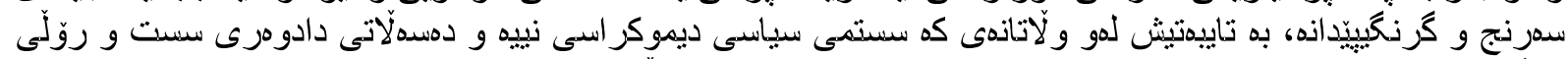

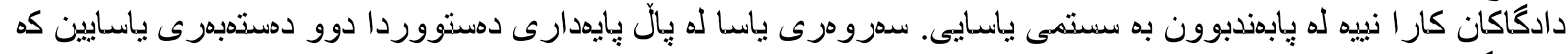

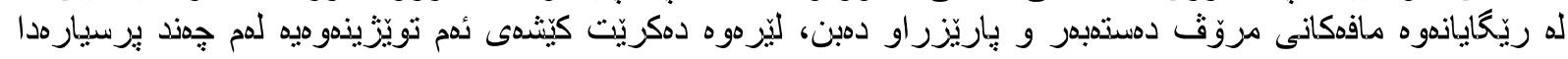

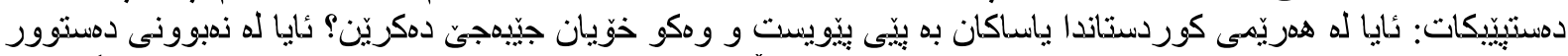

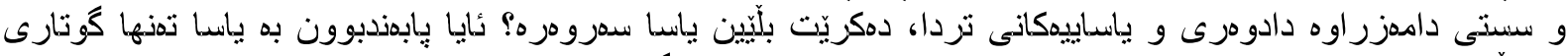

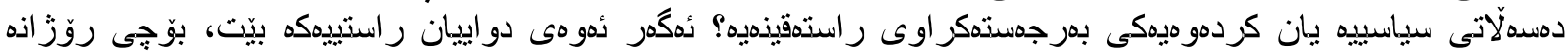

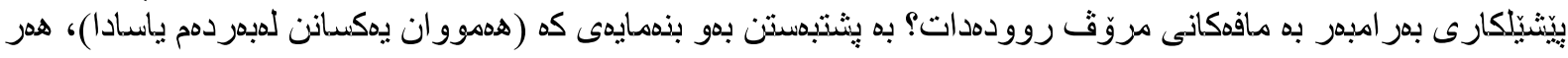

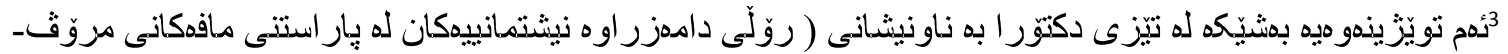

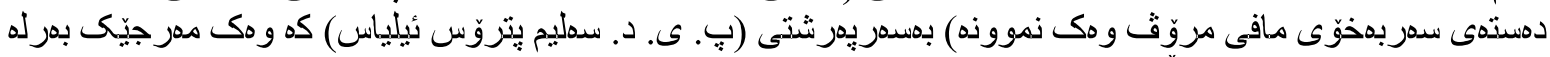




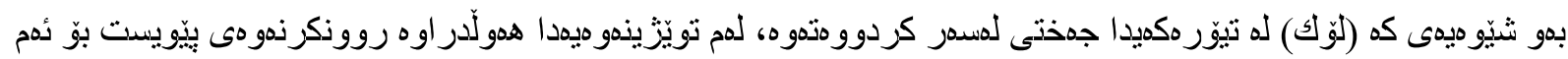

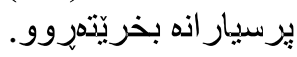
1

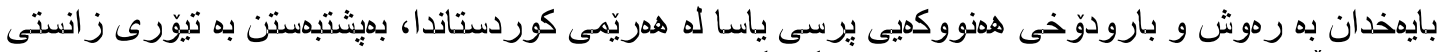

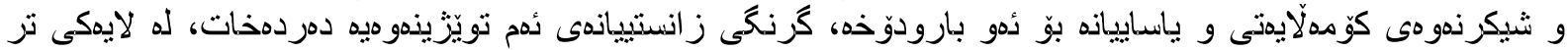

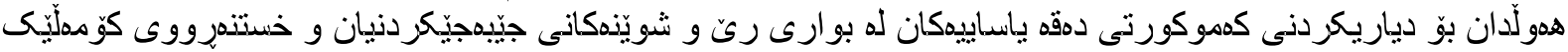

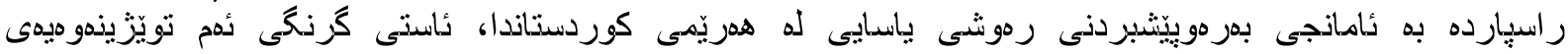
زياتزكردووه.

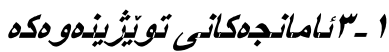

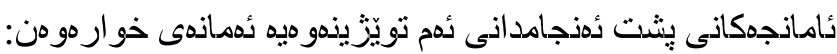

•روونكردذهو ميى ئاستى بِر اكتيز هكردنى ياساكان وهى خوّيان له همريّمى كوردستاندا .

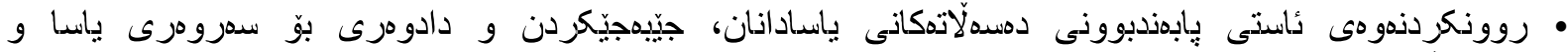

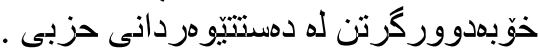

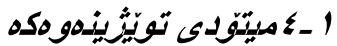

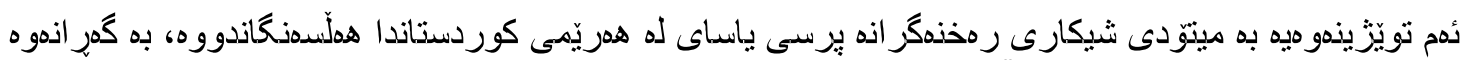

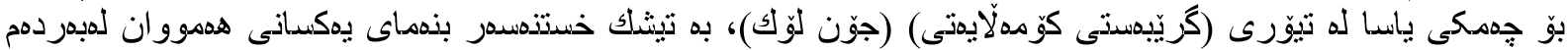

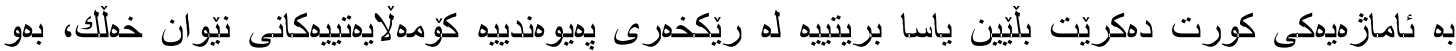

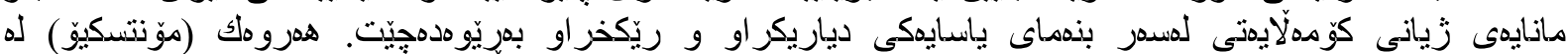

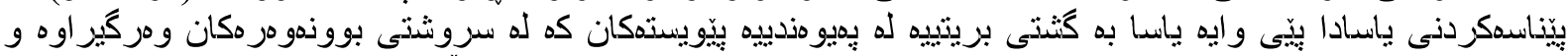

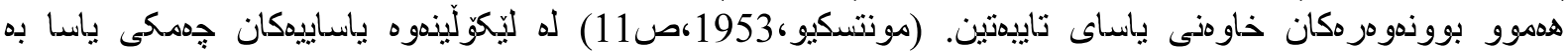

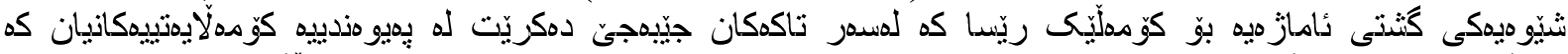

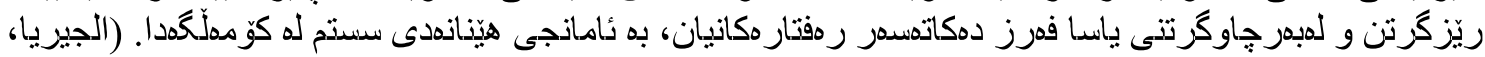

2

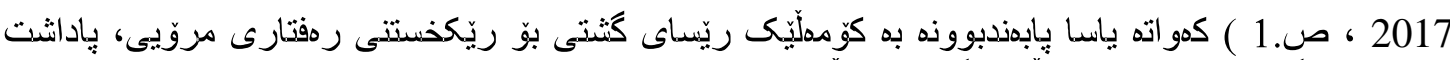

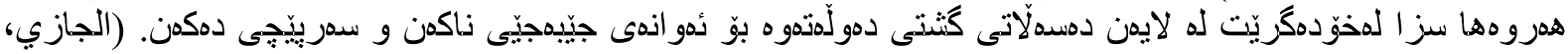

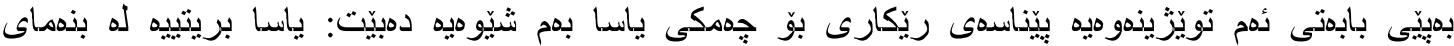

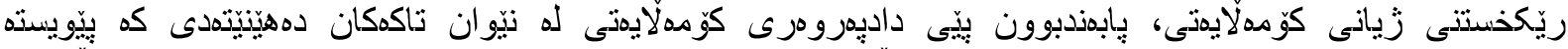

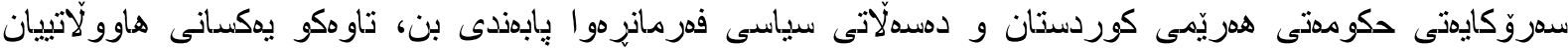

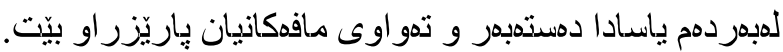

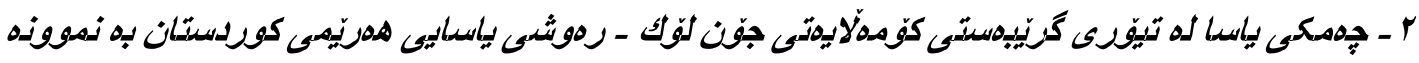

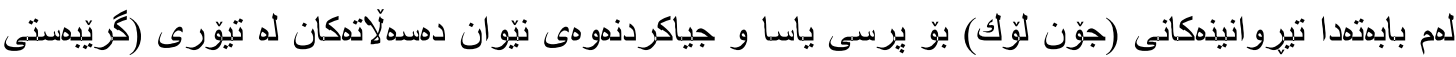

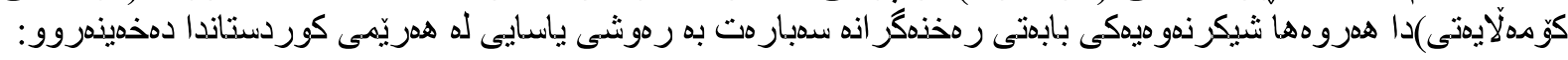

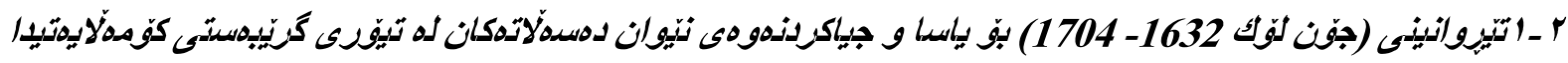

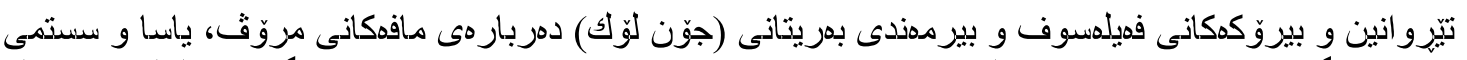

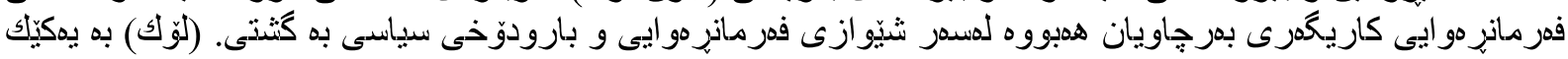




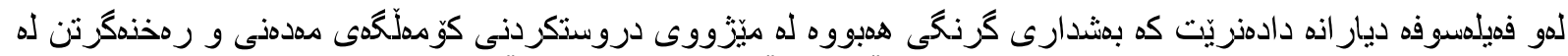

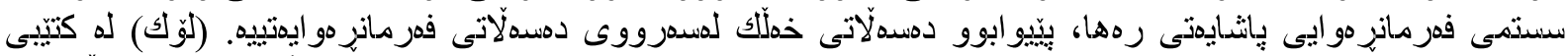

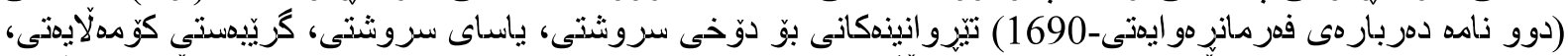

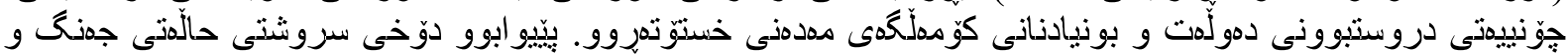

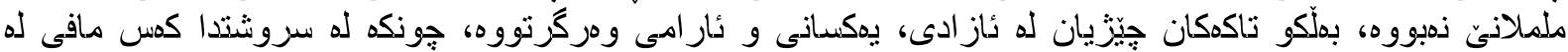

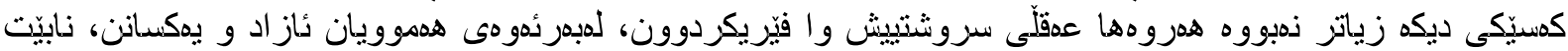

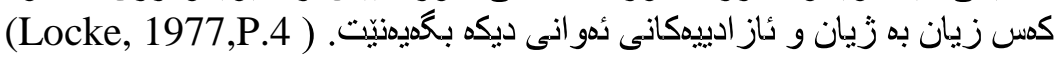

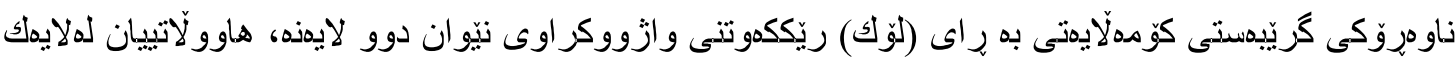

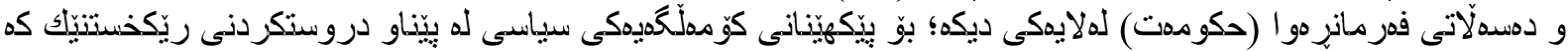

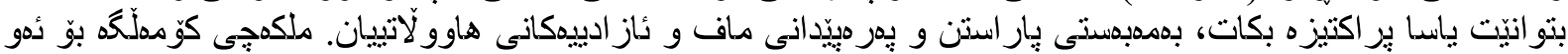

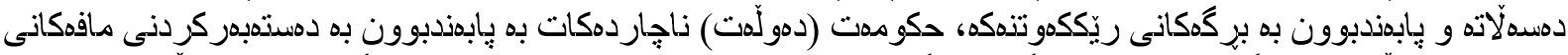

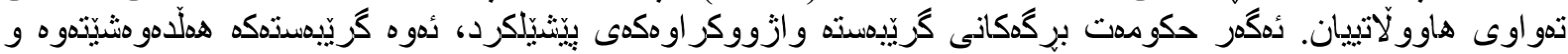

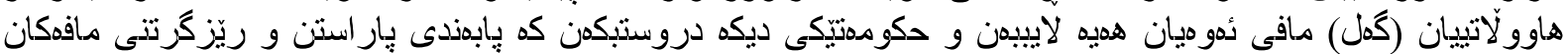

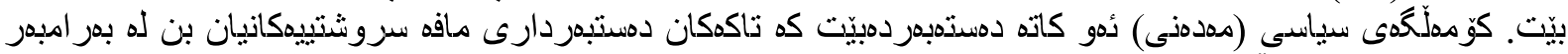

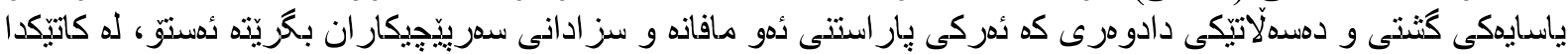

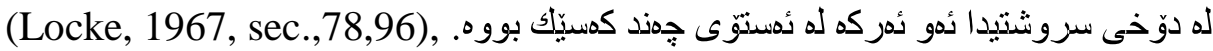

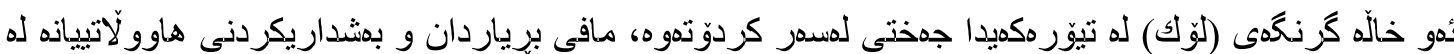

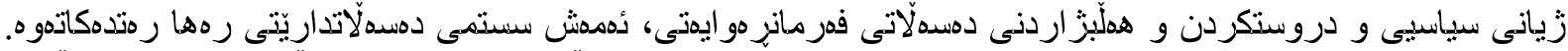

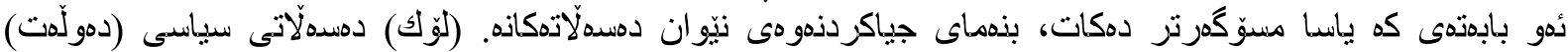

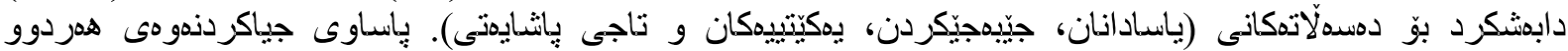

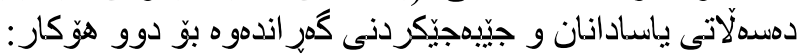

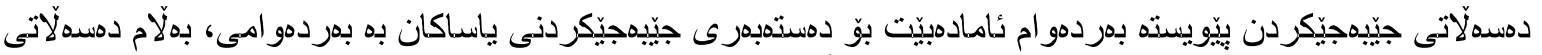

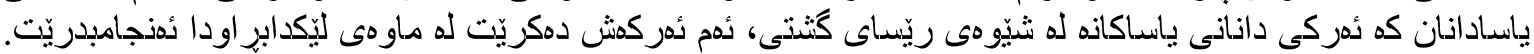

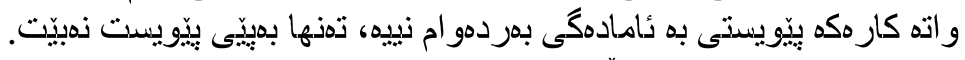

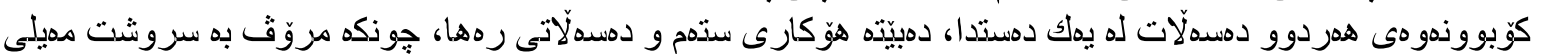

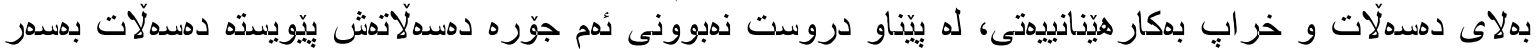

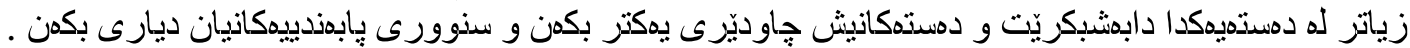

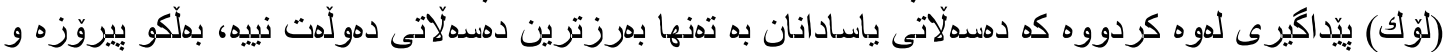

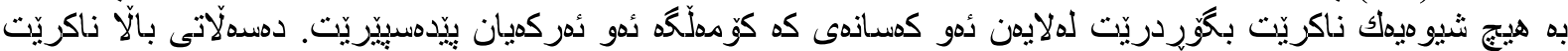

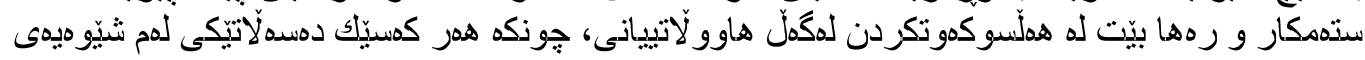

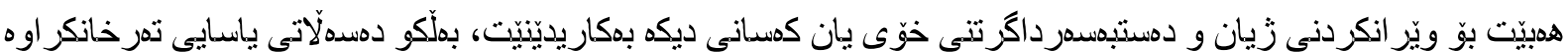

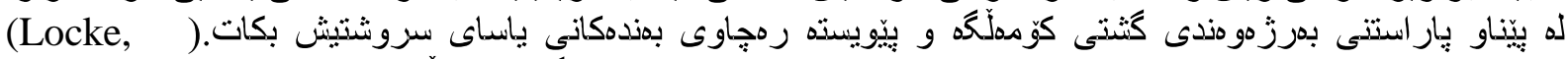

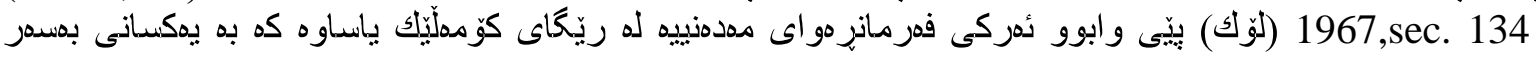

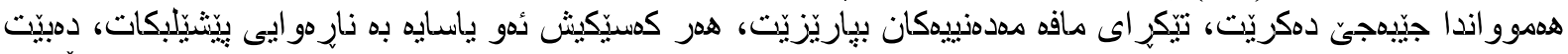

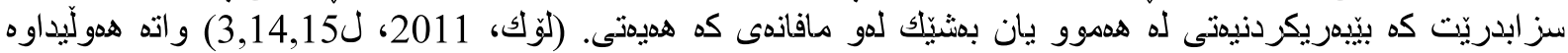

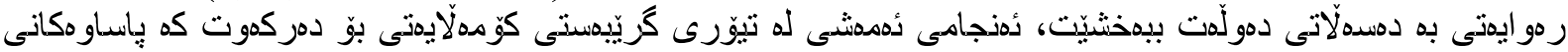

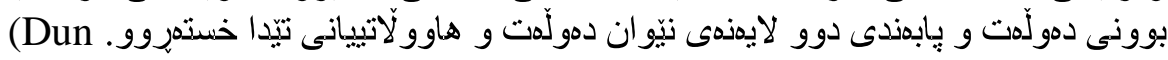

fee et al, 1999,p.14,33)

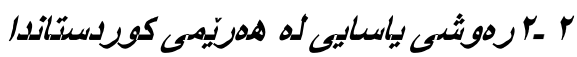

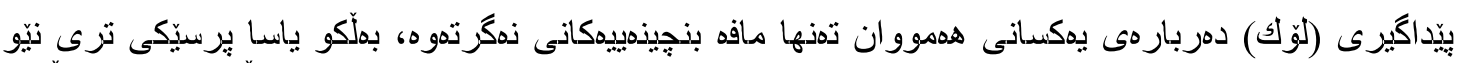

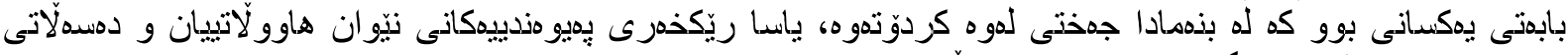

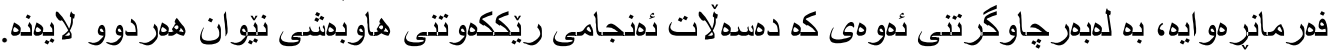

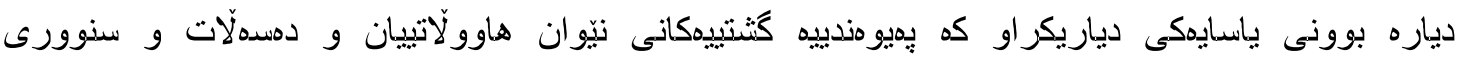

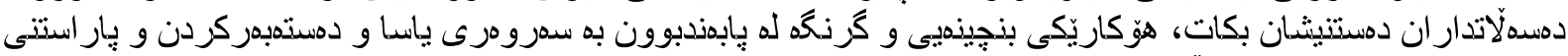

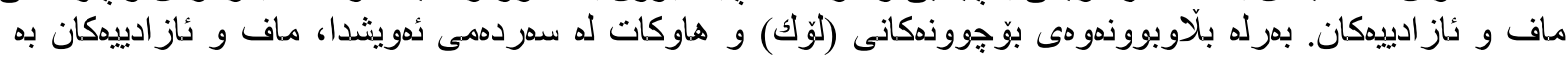

International Journal of Kurdish Studies Vol.5/1 ( January 2019) 
ياساييكر اون له ديارترينيان (بديماننامهى مدزن Magnacarta1215) (M ARSHALL, 1998,p.568) و ( 1628 ) AL- Aqaileh,n.d.,p.39) (Bill of Rights-1689) (قرقور، (Petition of Rights-

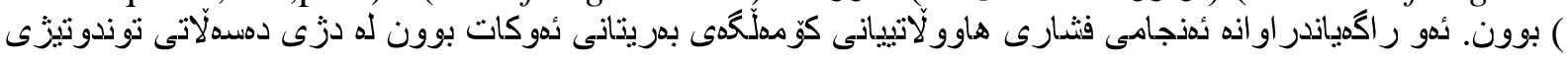

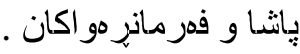

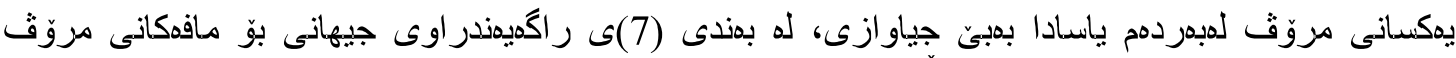

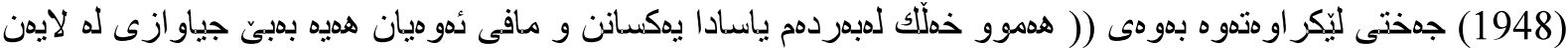

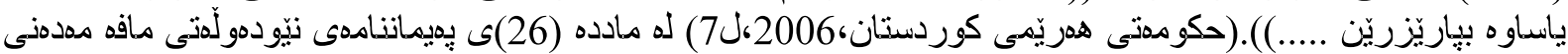

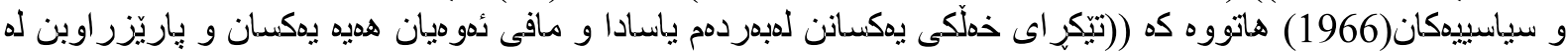

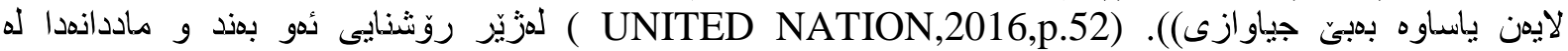

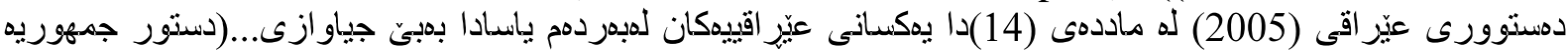

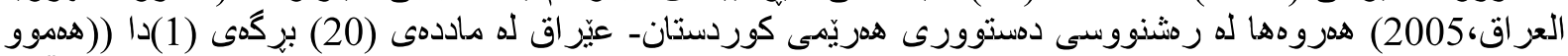

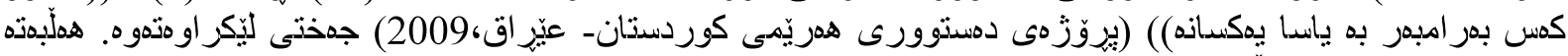

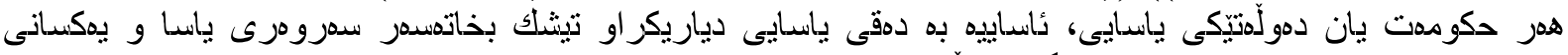

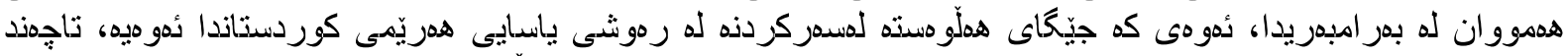

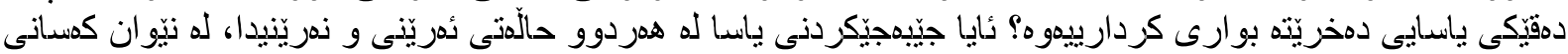

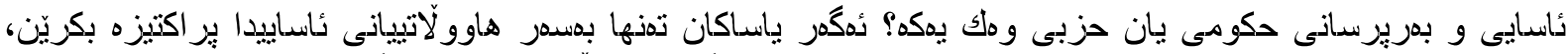

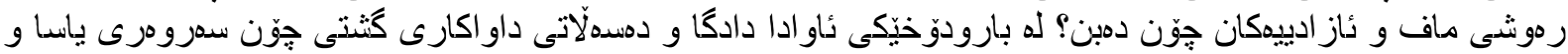

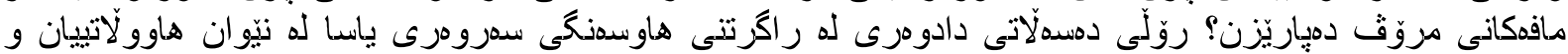

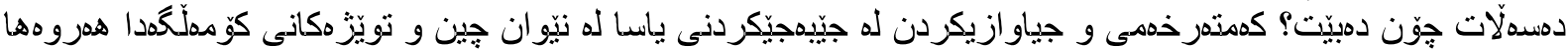

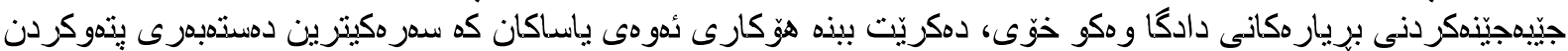

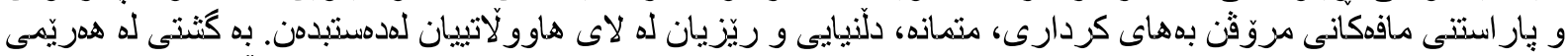

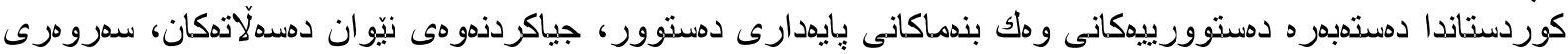

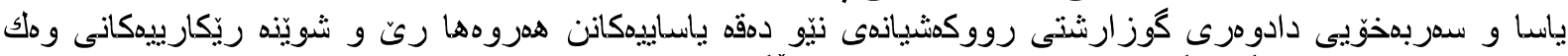

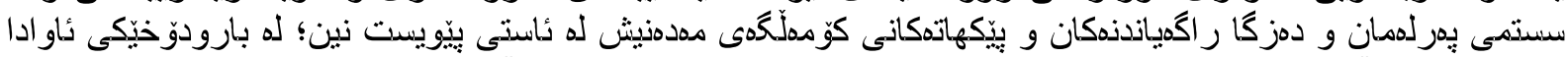

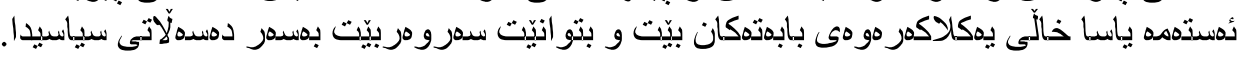

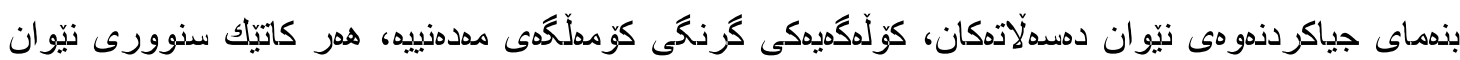

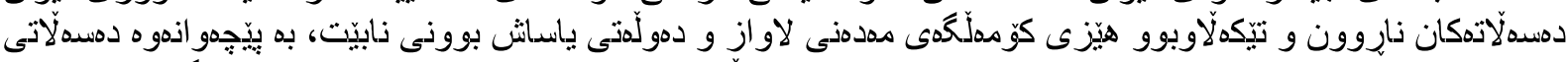

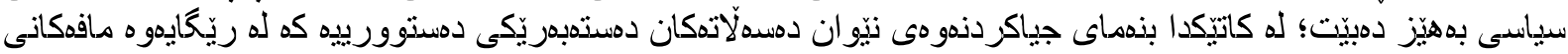

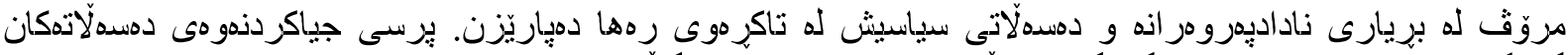

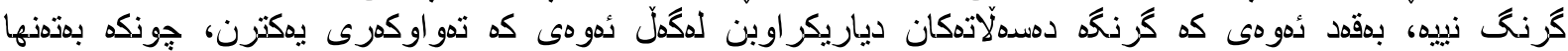

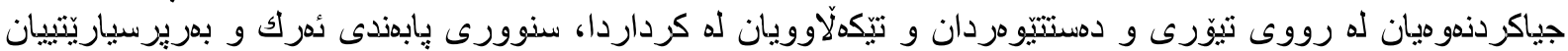

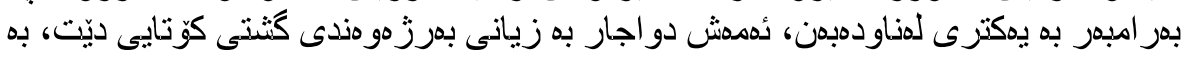

4

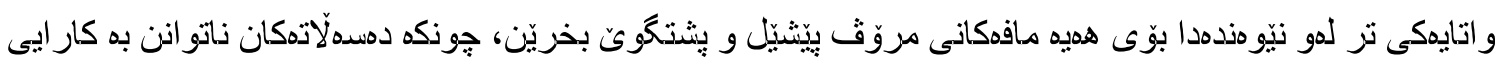

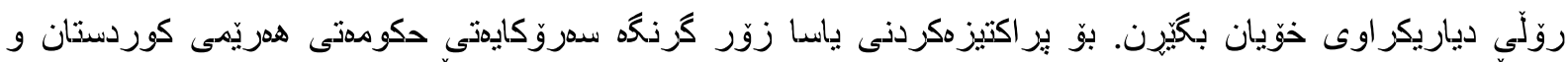

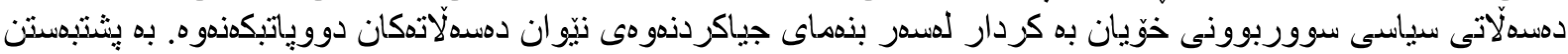

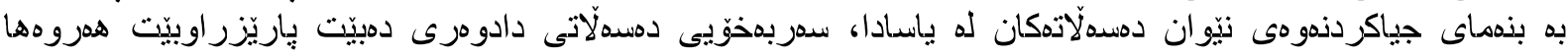

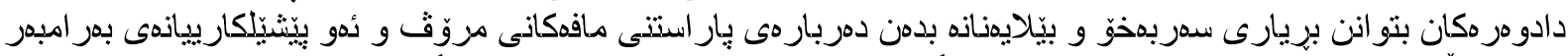

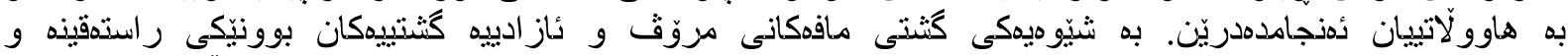

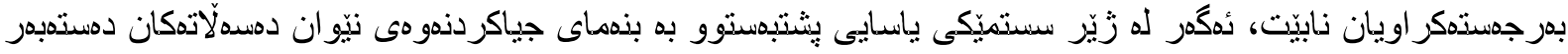

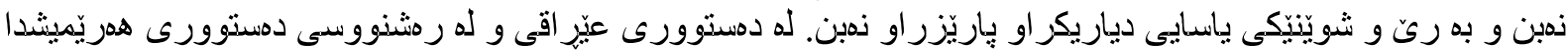

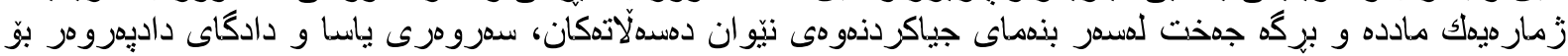

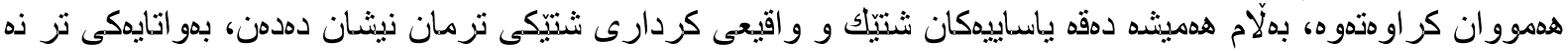

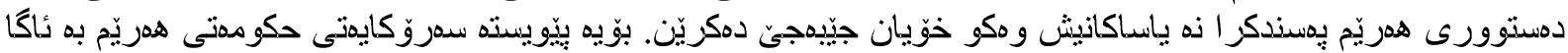

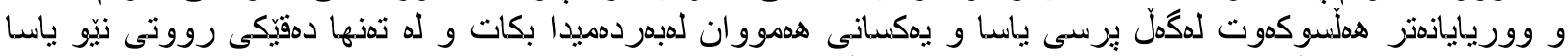

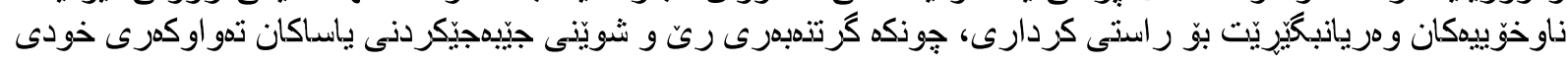




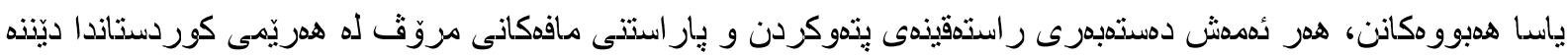
ئار اوه .

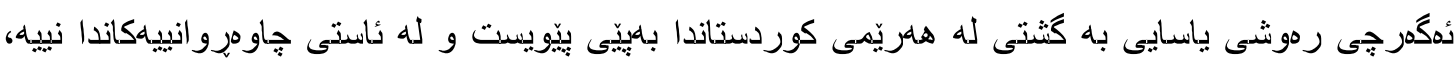

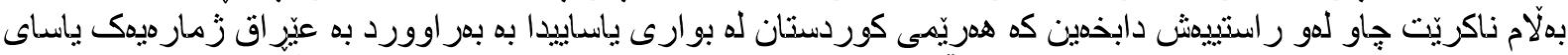

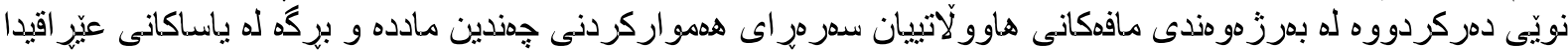

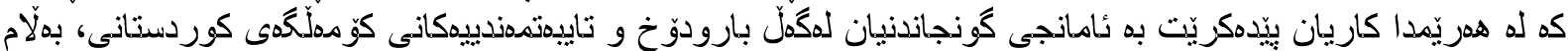

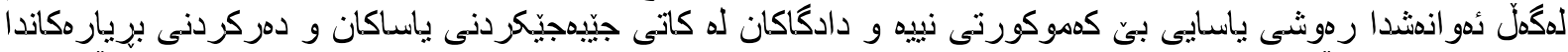

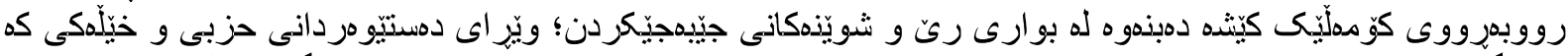

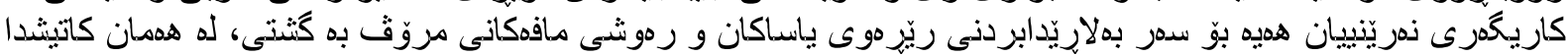

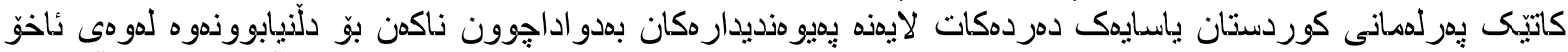

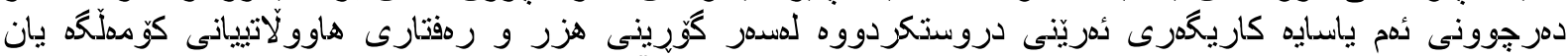

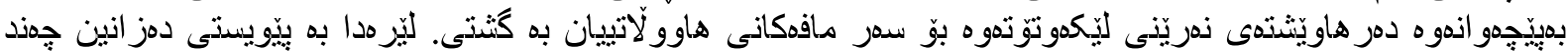

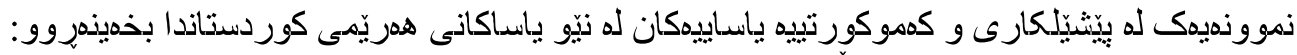

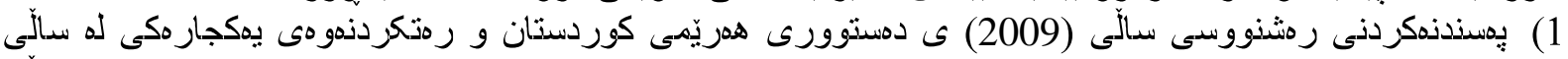

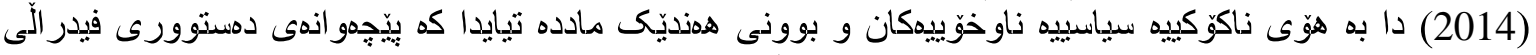

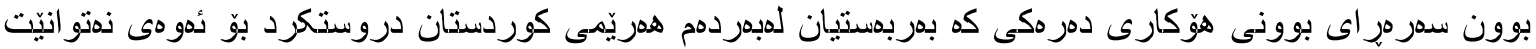
دمستوور هكه بخاته ر إيرسييهو بونه

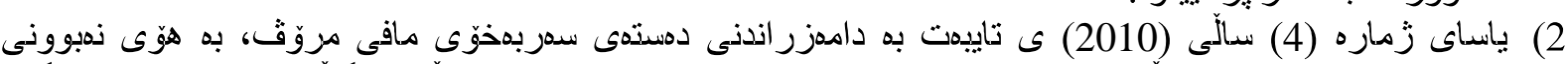

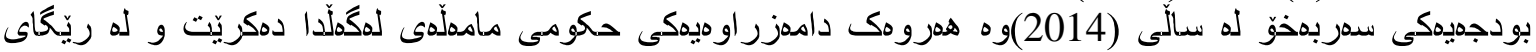

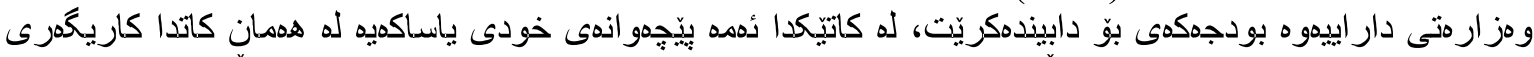

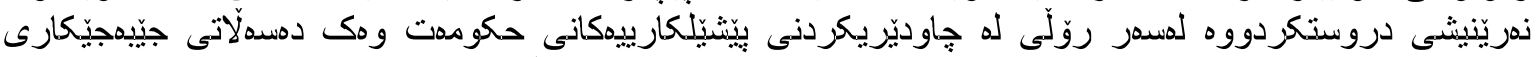

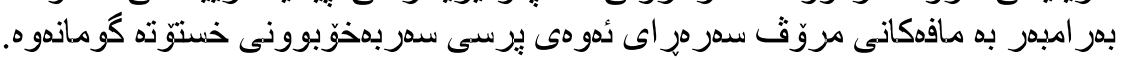

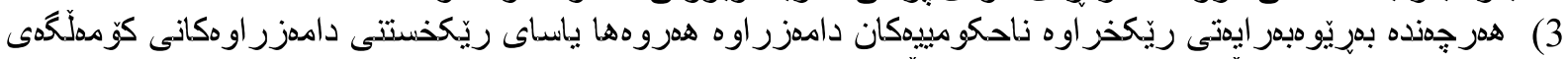

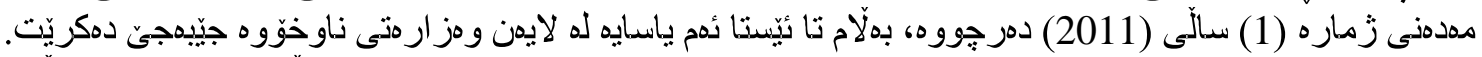

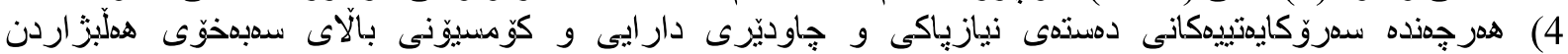

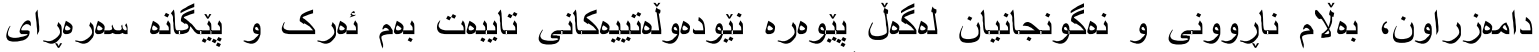

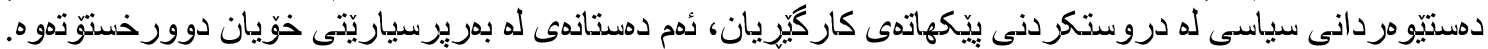

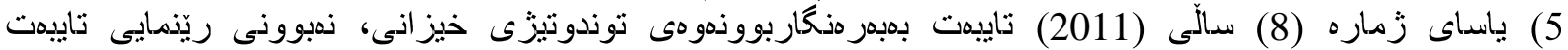

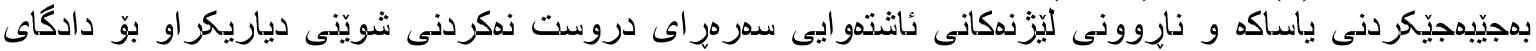

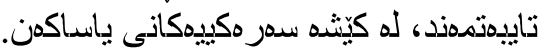

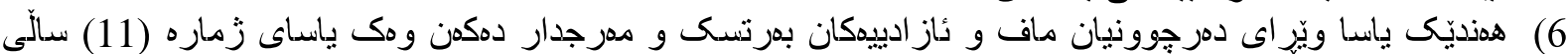

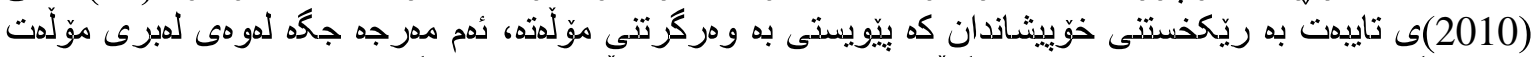

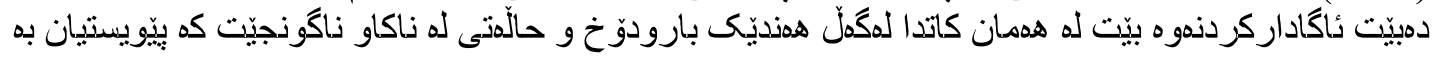

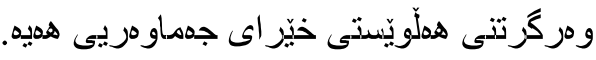

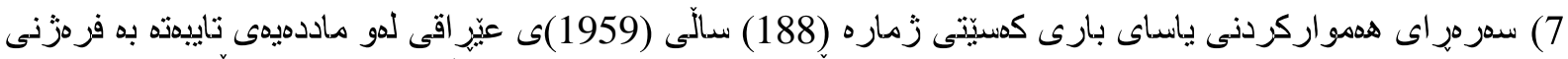

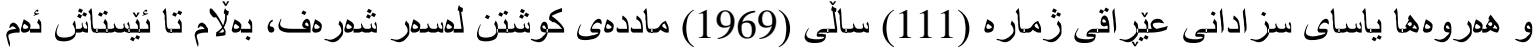

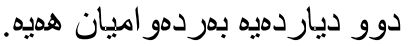

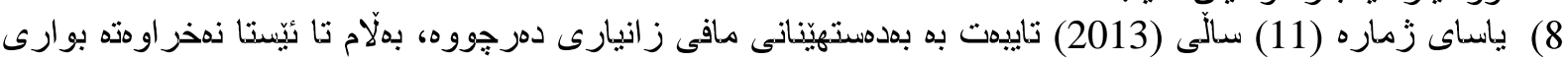

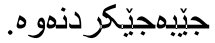

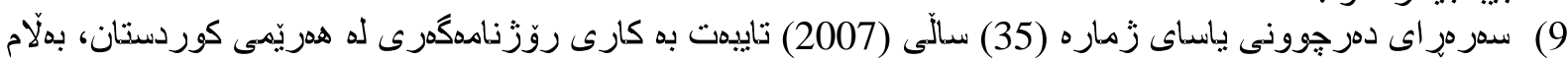

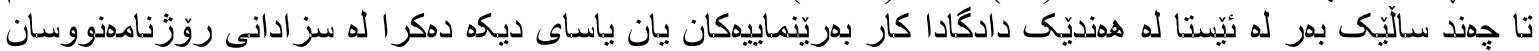

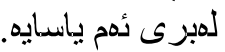




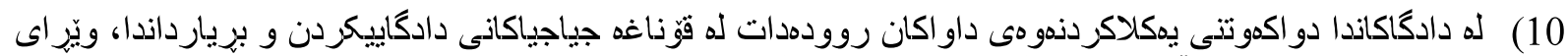

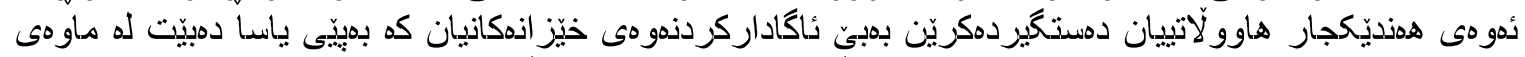

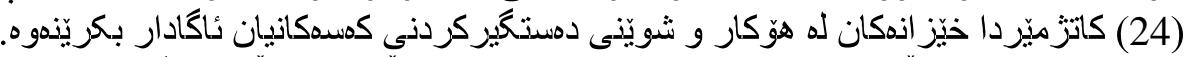

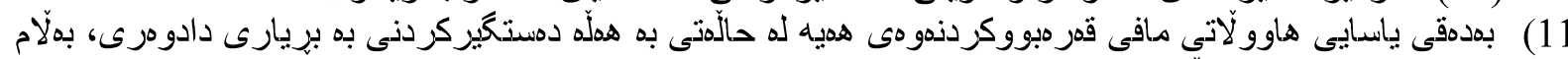

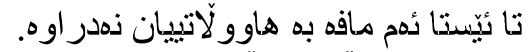

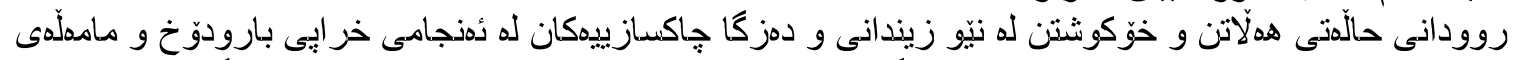

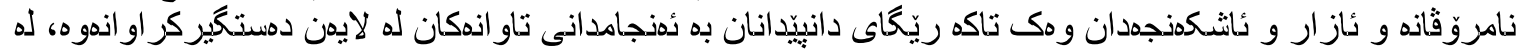

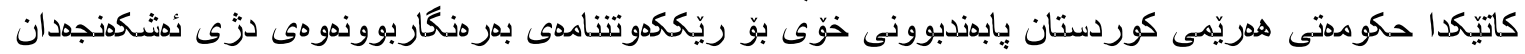

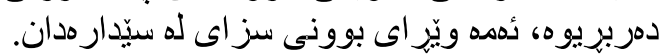

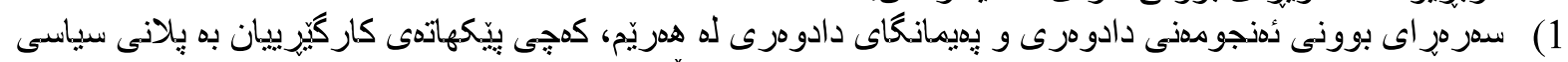

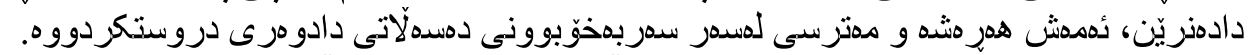

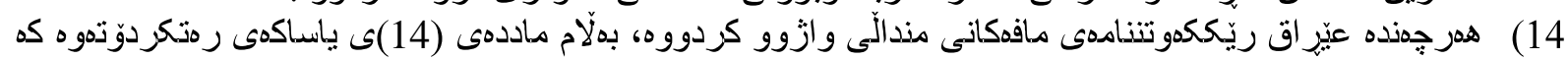

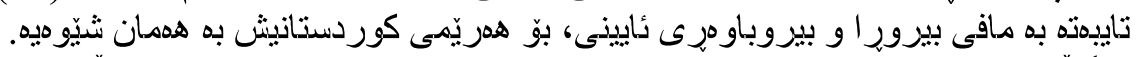

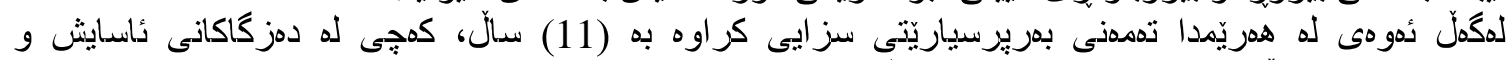

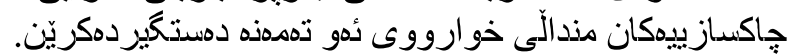

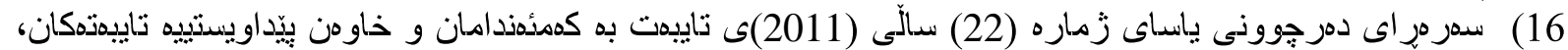

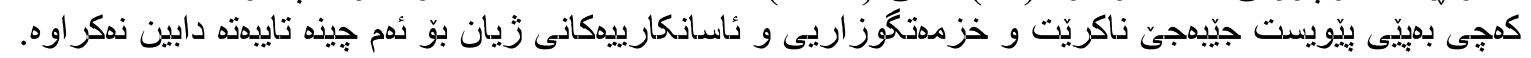
(UPR, 2014)

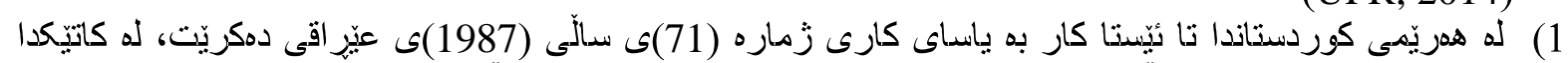

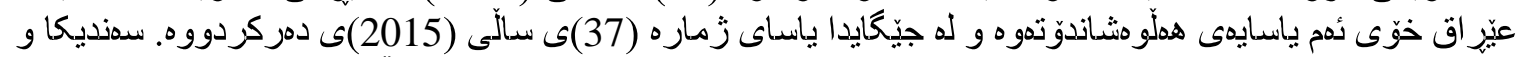

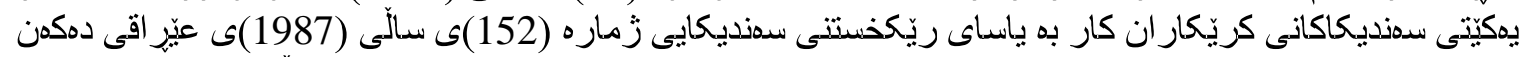

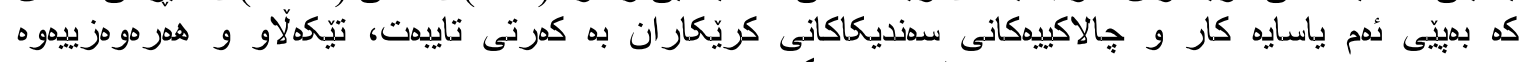

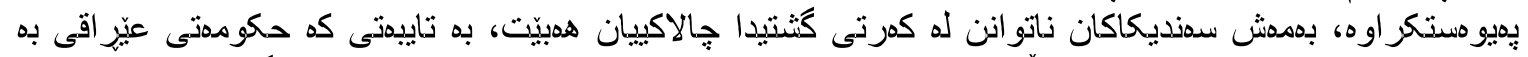

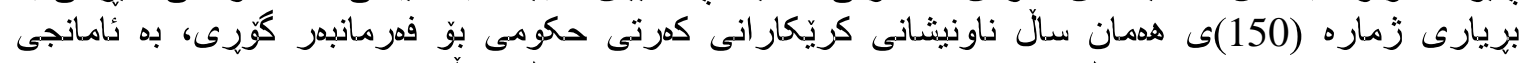

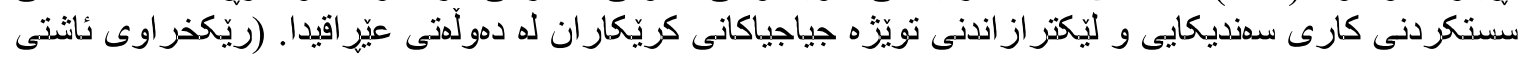
و و ئاز ادى، 2017)

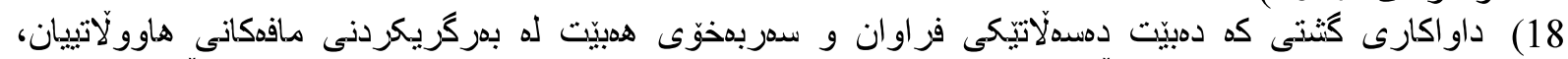

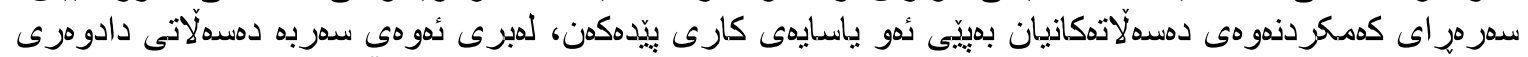

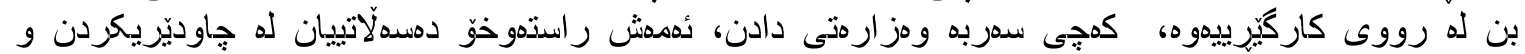

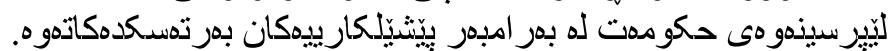

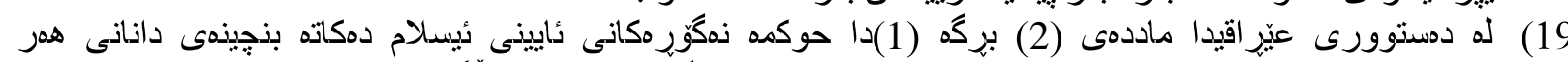

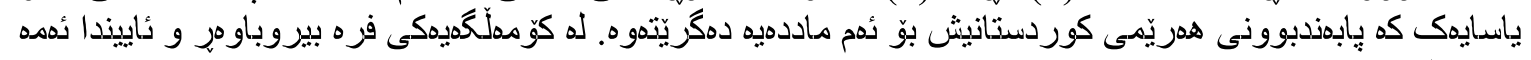

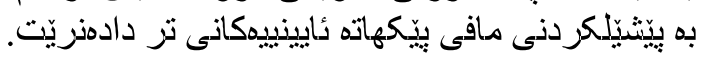

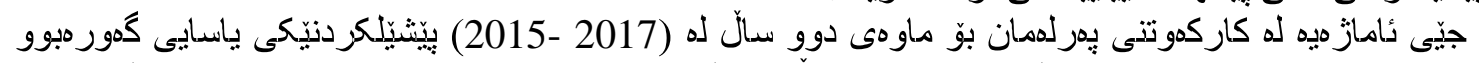

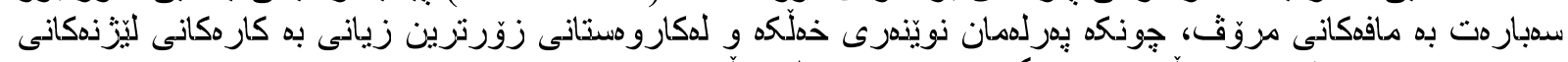

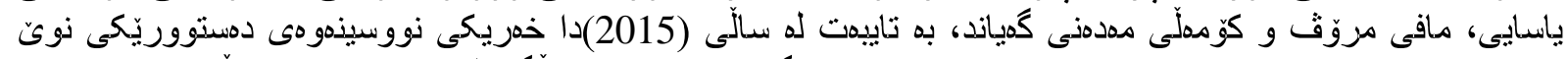

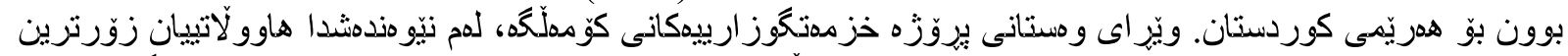

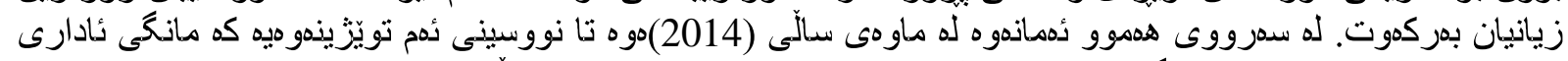

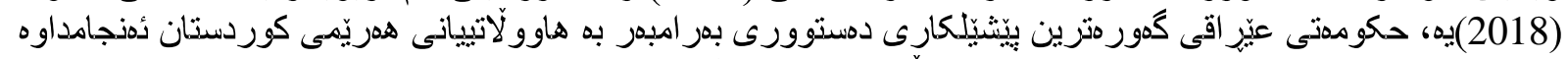

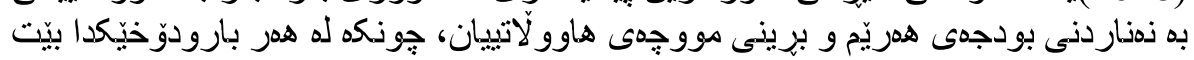

6

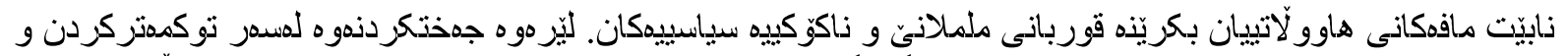

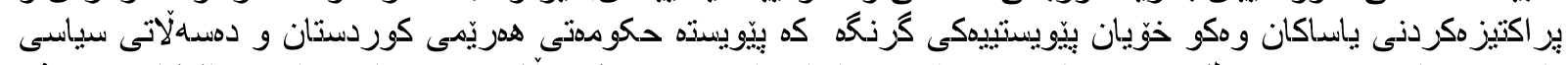

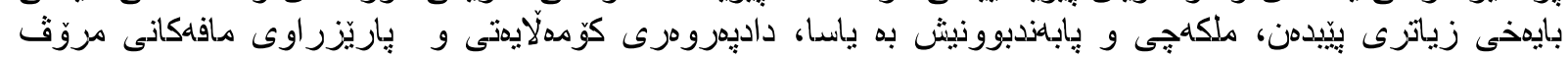
دمستمبهر دمكن.

دهرئدنجامدكانى تويزّيذهونكه

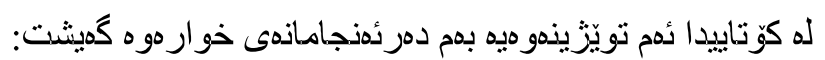




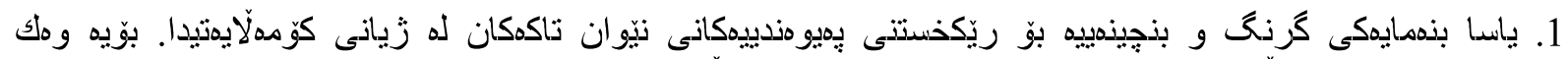

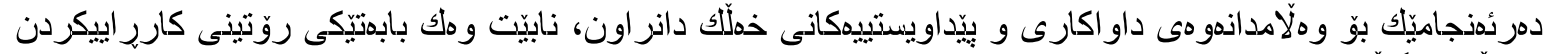

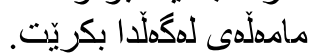

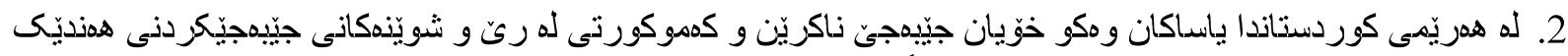

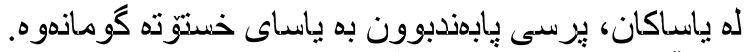

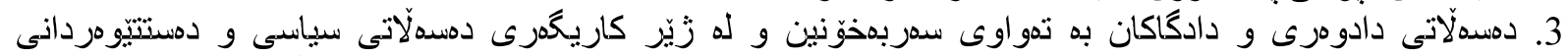

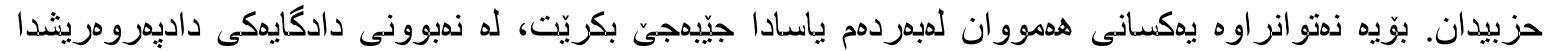

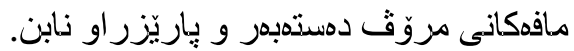

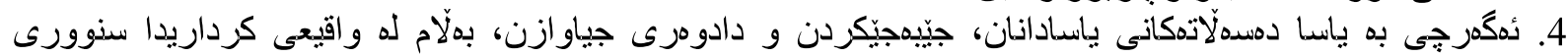

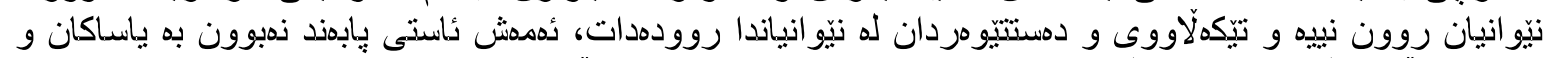

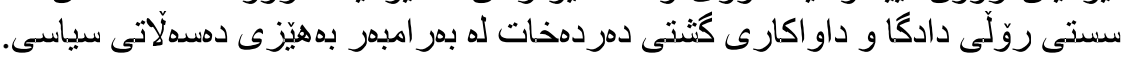

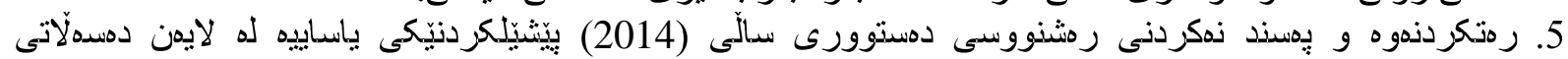

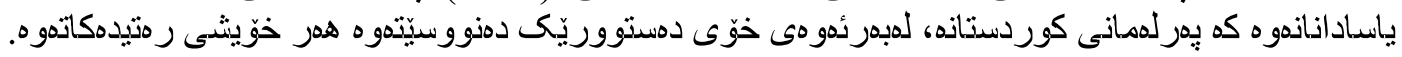

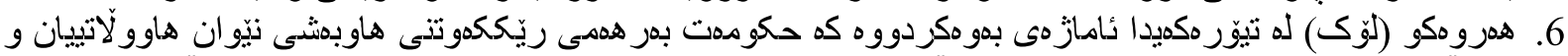

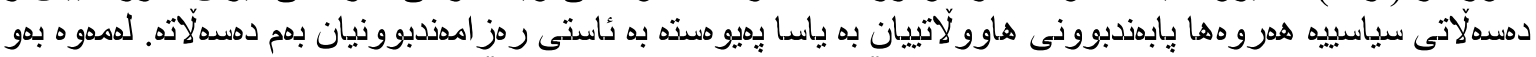

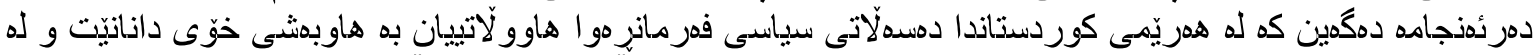

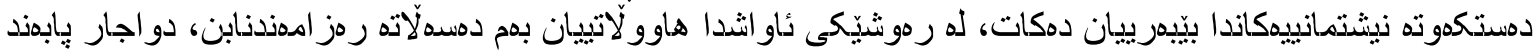

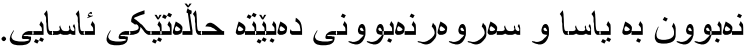
راسباردهكانى تويَزيذهوهكه

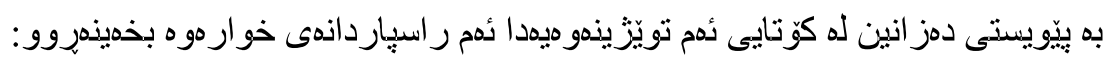

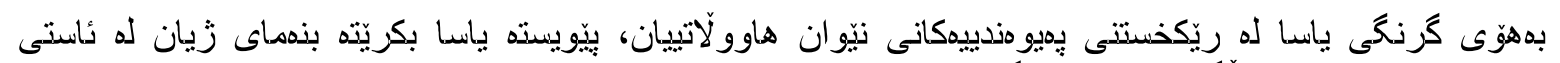

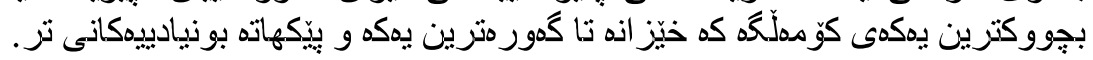

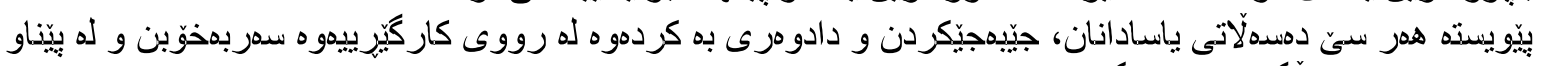

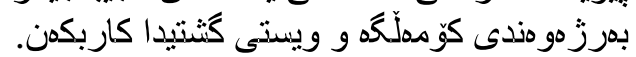

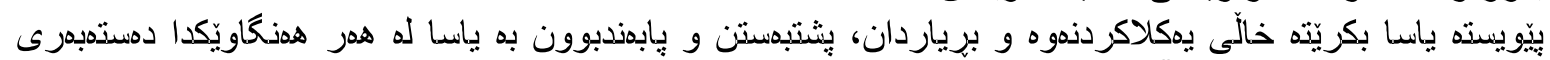

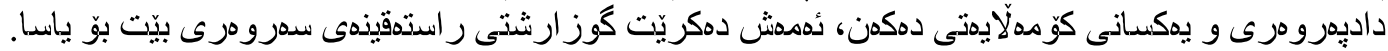

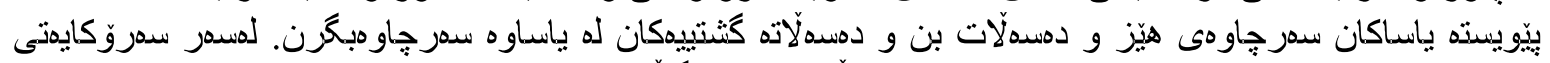

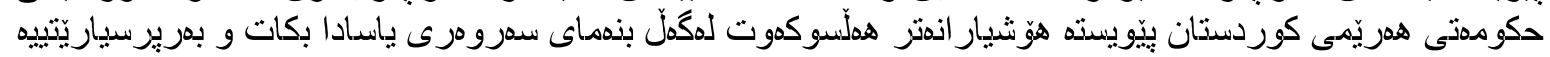

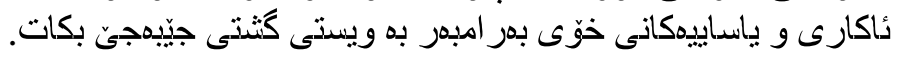

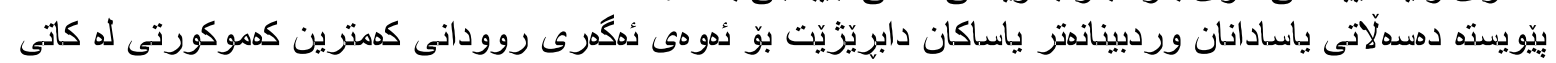
جيّيهجيَكردنياندا همبيّيت.

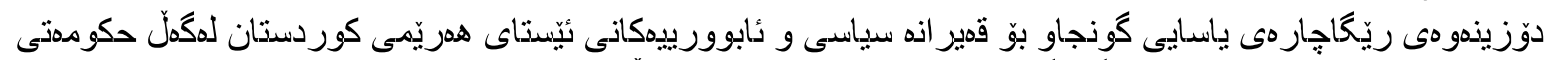

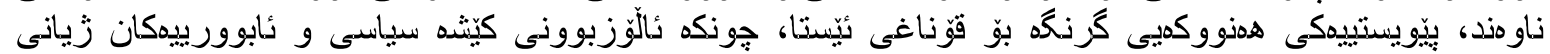

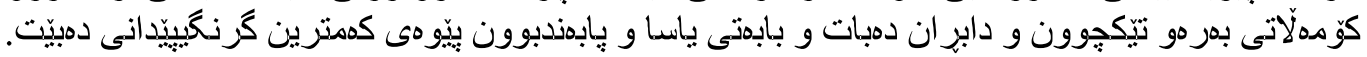

\section{References}

Al-Aqaileh, Ziad (n.d). Terminology of law, Amman publisher and distributor.

Dunfee, Thomas W., Smith, N.Craig Ross and Ross Jr, William T. (1999). Social Contracts and Marketing Ethics, Journal of marketing, 63(3).

Al-Jiria, Star, (2012). Concept of law, taken from http:s// www.staralgeria.net/t1922-topic on 14th of March 2018. 
Al-jazy, Hayl (2017). Definition of law: language and terminology, taken from http:s// www.mawdoo3.com

Kurdistan region government, The Ministry of Human Right, (2006). Human Rights Declaration, Karwan print, Erbil.

Locke, John, (2011). A letter concerning tolerance, ed: Ali, Abdulrezaq, Erbil Arass press and print. Erbil.

Locke, John, (1967). Tow Treatises of Government, ED: Peter, asle H., S.L.: Cambridge University Press.

Locke, John, (1977). The second treatise of government, ed: peardon, thomas p., s.l.: the library of arts.

Montesquieu, (1953). The spirit of law, ed: Zahitar, Adl, Cario, international commission for translation of human flags.

Marshall, Gordon, (1998). A Dictionary of Sociology (2eded.), New York: Oxford University Press.

Qrqur, Nabil, (2010). Human rights between western and Islamic conception, Al-Azaritta, new university House.

Submission the UN Universal periodic Review Eighth session of the UPR working Group of the Human Rights council, (2014). UPR October, IRAQ- Kurdistan Region.

The freedom of syndication and the reality of trade unions in Iraq and Kurdistan region, peace and freedom organization, (2017). Erbil.

The constitution of the public of Iraq, (2005).Baghdad, Iraqi representative council.

The draft of constitution of Kurdistan region- Iraq, (2009). Erbil, taken from http://www.krp.org/docs/draftconst Kurdish on 12th of January 2017.

United nation, the core international human rights treaties, (2016). Ed : Human rights office United Nations Assistance Mission for Iraq.

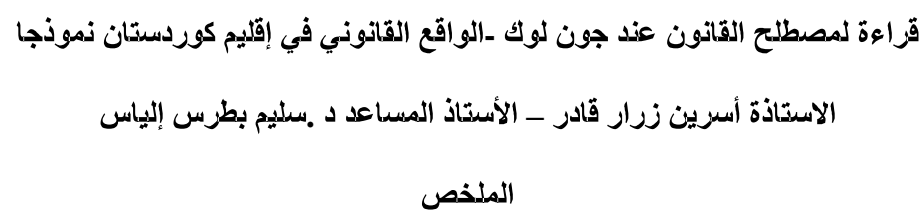




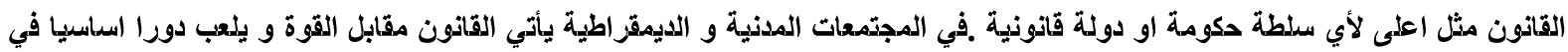

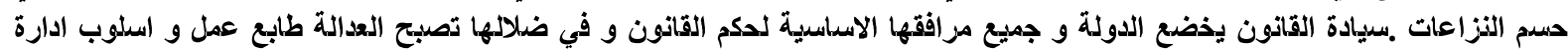

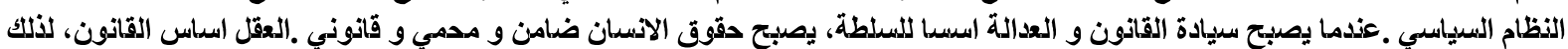

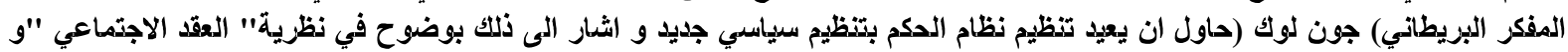

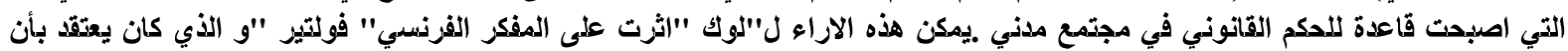

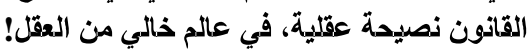
المفاهيم الاساسية :القانون، السلطة السياسية، العدالة الاجتماعية، حقوق الاتسان، المساواة . 